\title{
Micro resonant force gauges
}

\author{
Harrie A C Tilmans, Miko Elwenspoek and Jan H J Fluitman \\ MESA Research Insidute, Unwersity of Twente, $P O$ Box 217, 7500 AE Enschede (Netherlands)
}

(Recelved September 5, 1991, accepted September 27, 1991)

\begin{abstract}
A review of micro resonant force gauges is presented A theoretical description is given of gauges operatıng in a flexural mode of vibration, including a discussion of non-lınear effects Gauge factor and quality factor are defined and their relevance is discussed Performance issues such as sensitivity, stability and resolution are addressed Design aspects, including the means for excitation and detection of the vibration, and examples of silicon microfabrication technologies are described
\end{abstract}

\section{Introduction}

A micro resonant force gauge comprises a (small) vibratıng mechanical element, $1 \mathrm{e}$, the resonator, which converts an externally applied (ax1al) force into a shift of the resonance frequency of the element It is used as a sensing device for measuring quantities such as pressure, force (weight), mass flow, temperature or acceleration The term micro refers to the method of realization, $1 \mathrm{e}$, (silicon) microfabncation technologies Resonant force gauges can be used directly as sensors to convert the unknown applied force into a frequency-shuft output They can also form the heart of a sensor, for instance, be applied as strain gauges, where the measurand is first converted into a strain, which is subsequently converted into a frequency-shift of the resonant gauge Generally speaking, micro resonant force gauges belong to the class of resonant sensors [1, 2] Resonant sensors are very attractive in the precision measurement field, because of their high sensitivity and resolution, and further because of their sem1-dig1tal output, $1 \mathrm{e}$, a frequency shift, which eliminates problems such as intensity fiuctuations associated with analog signals

In general, the resonance frequency of a mechancal structure is affected by a perturbation of its potential or kınetic energy [3] Potential energy perturbations can be caused by mechanically straining the resonator or by changing the shape, and thus the stiffness, of the resonator In a resonant force gauge, the frequency shift is a result of potential energy perturbations caused by mechantcal strain To avoid error readings, kinetic energy perturbations, e g, caused by a change of the resonator mass or by changes of the density of the surrounding medium, should be eliminated This can be done by hermetically sealing the resonator in an evacuated or inert cavity to provide a stable environment

Although a resonant force gauge can have a variety of shapes and vibrate in various modes, the gauges considered in more detail in this paper are restricted to flexurally vibratıng elements that are mounted at two end points Special attention is paid to prismatic homogeneous beams that are clamped at both ends Analytical expressions are reviewed for the resonance frequencies of the beam, including a quantitative large-deflection analysis As a measure for the sensitivity of the gauge, gauge factors are defined and expressed in terms of dimensions and residual stress Further, the mechanisms of energy losses are discussed and ways of reducing them are indicated $A$ discussion of the various means of excitation and detection of the vibration is also included Finally, silicon fabrication technologies are bnefly reviewed and state of the art examples are given on how to fabricate sealed resonators For more information regarding applications and other aspects of resonant sensors, reference is made to a number of review articles 
written in recent years [1-6] Specifics of quartz resonatıng sensors are not a subject of this paper, but can be found in the literature [7-9]

\section{Resonance frequencies}

For an initially flat prismatic homogeneous beam, subjected to a (tensile) axial force $N$, the equation of motion governing the transverse deflection $w(x, t)$ as a function of the position $x$ along the beam length and the time $t$ is given by the following linear partial differential equation [10]

$\hat{E} I \frac{\partial^{4} w(x, t)}{\partial x^{4}}-N \frac{\partial^{2} w(x, t)}{\partial x^{2}}+\rho A \frac{\partial^{2} w(x, t)}{\partial t^{2}}=q(x, t)$

where $\hat{E}$ and $\rho$ are the 'effective' Young's modulus [11] and specific mass of the beam material, $A$ and $I$ the cross-sectional area and second moment of inertia, respectively, and $q(x, t)$ indicates the driving force per unit length To find the eigenfunctions or natural modes together with the corresponding eigenvalues or natural frequencies, the homogeneous part of eqn (1) is solved by employing a separation of variables approach in the form $w(x, t)=\phi(x) \exp (\jmath \omega t)$ Or, in other words, it is assumed that the beam is oscillatung at an angular frequency $\omega$ with a mode shape $\phi(x)$ For a clamped-clamped beam $(w(0, t)=w(l, t)=0$ and $w^{\prime}(0, t)=w^{\prime}(l, t)=0$, where $l$ is the length of the beam), non-trivial solutions are obtained if the following condition, $1 \mathrm{e}$, the characteristic equation, is satisfied

$\cos (\lambda l) \cosh (\mu l)-\frac{1}{2}\left(\frac{\mu}{\lambda}-\frac{\lambda}{\mu}\right) \sinh (\mu l) \sin (\lambda l)=1$

where

$\lambda l=k l\left[\left(a^{2}+1\right)^{1 / 2}-a\right]^{1 / 2}$

$\mu l=k l\left[\left(a^{2}+1\right)^{1 / 2}+a\right]^{1 / 2}$

and

$a=N / 2 \hat{E} I k^{2}$

$k^{4}=\rho A \omega^{2} / \hat{E} I$

This yields the following expression for the mode shape functions

$$
\begin{aligned}
\phi(x)= & \cos (\lambda x)-\cosh (\mu x)+\frac{\cos (\lambda l)-\cosh (\mu l)}{\frac{\lambda}{\mu} \sinh (\mu l)-\sin (\lambda l)} \\
& \times\left(\sin (\lambda x)-\frac{\lambda}{\mu} \sinh (\mu x)\right)
\end{aligned}
$$

The characteristic eqn (2) is satisfied for a discrete set of solutions yielding a discrete number of values for $k, 1 \mathrm{e}, k_{n}$ for $n=1,2$, The corresponding natural frequencies or eigenfrequencies $\omega_{n}$ are found from eqn (4) and the associated mode shapes $\phi_{n}$ from eqn (5) Because of the transcendental nature of the characteristic equation, a closed-form expression for the natural frequencies as a function of the axial load $N$ and the beam parameters cannot be obtained Approximate solutions can be found, for example, by employing Rayleigh's energy method [12] The following expression for the natural frequencies can be obtained this way

$\omega_{n}(N) \approx \omega_{n}(0)\left(1+\gamma_{n} \frac{N l^{2}}{12 \hat{E} I}\right)^{1 / 2}$

where

$\omega_{n}(0)=\frac{\alpha_{n}^{2}}{l^{2}}\left(\frac{\hat{E} I}{\rho A}\right)^{1 / 2}$

and the coefficients $\alpha_{n}$ and $\gamma_{n}$ can be found from

$\alpha_{n}{ }^{2}=l^{2}\left(\int_{0}^{l}\left(\frac{\mathrm{d}^{2} \tilde{\phi}_{n}(x)}{\mathrm{d} x^{2}}\right)^{2} \mathrm{~d} x / \int_{0}^{l}\left(\tilde{\phi}_{n}(x)\right)^{2} \mathrm{~d} x\right)^{1 / 2}$
$\gamma_{n}=\frac{12}{l^{2}}\left(\int_{0}^{l}\left(\frac{\mathrm{d} \tilde{\phi}_{n}(x)}{\mathrm{d} x}\right)^{2} \mathrm{~d} x / \int_{0}^{l}\left(\frac{\mathrm{d}^{2} \tilde{\phi}_{n}(x)}{\mathrm{d} x^{2}}\right)^{2} \mathrm{~d} x\right)$

where $\tilde{\phi}_{n}(x)$ represents an approximate shape function for a particular mode $n$ When $\tilde{\phi}_{n}(x)$ corresponds to the exact shape function, eqn (6) yields the exact value for the natural frequency, otherwise the result of eqn (6) will always be an upper bound of the natural frequency [12] A good approximation for the natural frequencies of a beam subjected to a non-zero axial load can be obtained if the shape functions of the same beam for zero applied axial load are substituted for $\tilde{\phi}_{n}(x)$ For a clamped-clamped beam, these functions are given by eqn (5) for $\lambda=\mu=k$, where $k$ is determined from eqn (2), which for $N=0$ reduces to $\cos (k l) \cosh (k l)=1$ For the fundamental mode this yields $\alpha_{1}=4730$ and $\gamma_{1}=0295$, and for the first harmonic, $\alpha_{2}=7853$ and $\gamma_{2}=0145$ This is 


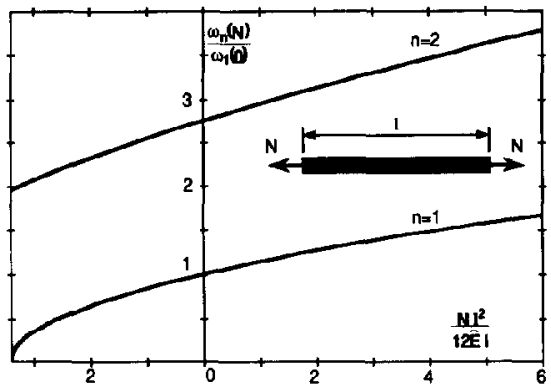

Fig 1 Normalized angular resonance frequency of the fundamental mode and the first harmonic as a function of the normalized axial force for an initially flat prismatic clamped-clamped beam, see also eqn (6)

graphically illustrated in Fig 1 The error in the approximation for the natural frequency is smaller than $05 \%$ if $\gamma_{n} N l^{2} / 12 \hat{E} I<1$ [13] An empirical correction in the form of an additional quadratic term in the axial force under the square root has been proposed by van Mullem et al [14]

In micromechanical devices, very often beams with a rectangular cross section and a large width $(b>5 h$ [15]) are used and eqns (6) $-(7)$ can conveniently be written as

$$
\begin{aligned}
\omega_{n}(N)= & \frac{\alpha_{n}{ }^{2}}{\sqrt{12}}\left(\frac{E}{\rho\left(1-v^{2}\right)}\right)^{1 / 2} \\
& \times \frac{h}{l^{2}}\left(1+\gamma_{n} \frac{N}{E b h}\left(1-v^{2}\right)\left(\frac{l}{h}\right)^{2}\right)^{1 / 2}
\end{aligned}
$$

where $v$ and $E$ are Poisson's ratio and Young's modulus of the beam material, respectively, and $b$ and $h$ are the width and thickness of the beam, respectively

In the model described above, effects due to shear deformation and rotary inertia are not taken into account These effects are negligible for slender beams, $1 \mathrm{e}$, beams with a large length/ thickness ratio and for small values of the mode number $n[12,16]$ Besides the shift in the resonance frequency as a result of the induced axial force, the frequency also changes slightly as a result of changes in the dimensions of the beam The latter effect, however, is small compared to the effect of the induced axial force (see also Section on gauge factors) Further, the model does not apply for beams with a non-zero initial deflection, e g, beyond the Euler buckling point
In this case, additional terms have to be included in the equation of motion $[13,17]$ The effect of an elastic support on the resonance frequencies was discussed by Bouwstra and Geljselaers [13], and the analysis showed that the support forms a reasonable stiffness against bending, but not against axial elongations The latter implies that, in the case of an elastic support, the frequency shifts are smaller than predicted by the equations above Torsional modes were discussed by Geijselaers and Tijdeman [18] The effects of damping terms and non-linear (large deflection) deformation are not accounted for here, but will be briefly discussed below

\section{Force, stress or strain?}

The resonance frequencies of doubly supported beams respond to the applied axial force $N$ This is easuly understood from an inspection of the equation of motion of the beam, eqn (1) The frequency dependence is expressed by eqn (6) If the beam is used as a measuring device it can therefore be designated as a 'resonant force gauge' An illustrative example is the vibrating string of Wyman [19], where the external force, e $\mathbf{g}$, a weight, comprises the axial force responsible for the frequency shift of the string The force in this case is the independent variable, which induces an axial elongation of the string If the cross-sectional area $A$ does not change under the applied load, the gauge could also be designated as a 'resonant stress gauge', since the axial stress $\sigma$ in this case 1 directly related to the axial force $N \sigma=N / A$

In many applications, however, the axial force is a result of a displacement of the end points or elongation of the gauge, e g , see [20-29] Here, the induced axial force is directly related to the elongation $\Delta l$ or the strain $\Delta l / l$ of the gauge $N=E A(\Delta l / l)$, where $l$ is the length of the gauge The gauge truly senses a deformation of the supporting structure and is therefore referred to as a 'resonant elongation gauge' or 'resonant strain gauge' to emphasize the measuring principle and the origin of the axial force It also links devices employing resonant strain gauges to devices employing the more conventional (piezo) resistive strain gauges In these applications, the gauges are embedded into a supporting structure, the so-called 'load cell', e $g$, 
a diaphragm [24], or a supporting frame [14, 26], which converts the externally applied load, e $\mathrm{g}$, a pressure, into a strain in the gauge The contribution of the stiffness of the gauge to the overall stiffness of the device is generally negligible

\section{Gauge factors}

The gauge factor of a resonant gauge provides a measure of the gauge to the applied axial load The gauge factor $G_{N n}$, describing the sensitivity of the gauge, vibrating at $\omega=\omega_{n}$, to changes in the axial force $N$, and in the vicinity of the operating point $N=N_{0}$, caused by the biaxial residual stress $\sigma_{0}$ or residual strain $\varepsilon_{0}$, is defined by

$G_{N n} \equiv\left[\frac{1}{\omega_{n}} \frac{\partial \omega_{n}}{\partial N}\right]_{N=N_{0}=(1-v) \sigma_{0} A=E A \varepsilon_{0}}$

or, for a (w1de) beam with a rectangular cross section (see eqn (9))

$G_{N n}=\frac{1}{2}\left[\frac{\gamma_{n} \frac{\left(1-v^{2}\right)}{E b h}\left(\frac{l}{h}\right)^{2}}{1+\gamma_{n} \varepsilon_{0}\left(1-v^{2}\right)\left(\frac{l}{h}\right)^{2}}\right]$

If the axial force is a result of an axial elongation of the beam, it is more useful to define a gauge factor $G_{e n}$, describing the sensitivity of mode $n$ to changes in the strain $\varepsilon$ in the vicinity of the operatIng point $\varepsilon_{0}=(1-v) \sigma_{0} / E$

$G_{\varepsilon n} \equiv\left[\frac{1}{\omega_{n}} \frac{\partial \omega_{n}}{\partial \varepsilon}\right]_{\varepsilon=\varepsilon_{0}}$

or using eqn (9) with $N / E b h=\varepsilon$,

$G_{e n}=\frac{1}{2}\left[\frac{\gamma_{n}\left(1-v^{2}\right)\left(\frac{l}{h}\right)^{2}}{1+\gamma_{n} \varepsilon_{0}\left(1-v^{2}\right)\left(\frac{l}{h}\right)^{2}}\right]$

If the effects of geometrical deformations are taken into account $l^{\prime}=l(1+g)$ and $h^{\prime}=h(1-v \varepsilon)$, the gauge factor would be given by

$$
\begin{aligned}
G_{c n}^{\prime}= & -(2+v)+\frac{1}{2}\left(1+2 \varepsilon_{0}(1+v)\right) \\
\times & {\left[\frac{\gamma_{n}\left(1-v^{2}\right)\left(\frac{l}{h}\right)^{2}}{1+\gamma_{n} \varepsilon_{0}\left(1-v^{2}\right)\left(\frac{l}{h}\right)^{2}}\right] }
\end{aligned}
$$

The gauge factors $G_{s n}$ and $G_{g n}^{\prime}$ are approximately the same For zero residual strain $\left(\varepsilon_{0}=0\right), v=03$ and an aspect ratio $l / h=200$, they differ by $004 \%$ Or in other words, the shift in the resonance frequency as a result of geometrical deformation of the gauges is small compared to the shift caused by the axial stiffening This has an important consequence for the behaviour of resonant gauges that are subject to creep If creep occurs under a constant state of stress, for instance as in the expenment described by Bethe et al [30], the resonance frequency will only be slightly affected On the other hand, if the input load of the gauge is an elongation, creep will senously limit the performance of the device Also a possible relaxation of the residual stress during operation will cause error readings Study of the relaxation of residual stress in thin films used for the fabrication of microresonators should therefore be an important topic of future research

Large gauge factors are achieved at low residual strain/stress levels and/or for slender beams Also, the gauge factor decreases with increasing mode number This implies a larger contribution of geometrical deformations to the shift in the resonance frequency for the higher-order modes For the fundamental mode, the gauge factor given by eqn (13) is graphically shown in Fig 2

\section{Quality factor}

The mechanical quality factor $Q$ is a measure of the energy losses of the resonator or, in other

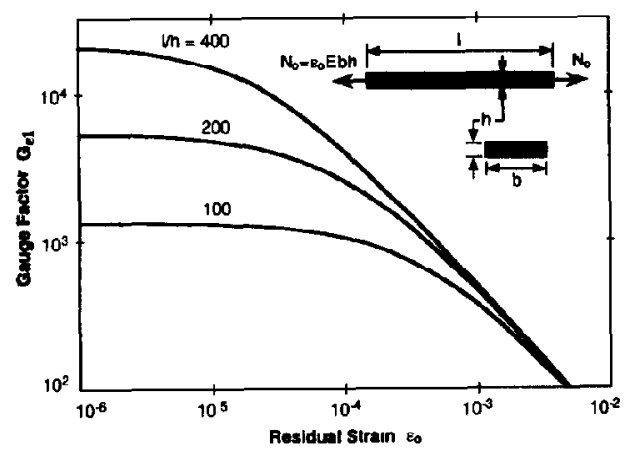

Fig 2 Gauge factor $G_{61}$ of the fundamental mode vs residual tensile strain $\varepsilon_{0}$ for a clamped-clamped beam with a rectangular cross section for three values of the slenderness ratio $l / h$ and $v=03$, see also eqn (13) 
words, a measure of the mechanical damping The $Q$-factor is defined as

$Q \equiv 2 \pi \frac{\text { maximum energy stored in one period }}{\text { dissipated energy per period }}$

Low energy losses imply a high $Q$-factor The $Q$-factor cannot be determined directly, but instead can be deduced from the response character1stics of the resonator One common method of determining $Q$ is from the steady-state frequency response plot of a resonator excited by a harmonic force with constant amplitude

$Q \cong \frac{\omega_{\text {res }}}{\Delta \omega_{-3 \mathrm{~dB}}}$

where $\omega_{\text {res }} 1$ s the resonance frequency, defined as the frequency of maximum amplitude response, and $\Delta \omega_{-3 \mathrm{~dB}}$ is the half-power bandwidth of the frequency response Equation (16) indicates that $Q$ is a measure of the sharpness or the frequency selectivity of the resonator A high $Q$-factor means a sharp resonance peak $\mathrm{A}$ high $Q$-factor for a resonant force gauge has several advantages The energy required to maintain oscillation is kept low, which reduces heat generation and opens up the possibility of powering the resonant gauges from alternatıve sources, e $g$, solar energy Further, a high $Q$ means a good frequency stability and the effects on the oscillation frequency of the electronic circuitry used to sustain the oscillation are mınımızed

Several mechanisms of energy loss can be identıfied (a) losses into the surrounding (fludd) medium, caused by acoustic radiation and viscous drag, (b) losses into the mount used to support the resonator due to motion of the mount, and (c) intrinsic damping caused by energy losses inside the material of the resonator The energy loss of each loss mechanism separately can be described by a corresponding quality factor $Q_{l}$, and the overall quality factor $Q_{\text {tot }}$ can be found from

$\frac{1}{Q_{\mathrm{tot}}}=\sum_{\mathrm{t}} \frac{1}{Q_{\mathrm{t}}}$

It is obvious from eqn (17) that $Q_{\text {tot }}$ cannot exceed the value of the smallest $Q$. The discussion below mainly deals with vibratıng beams Quality factors of vibrating diaphragms are discussed elsewhere [31]
The losses into the surrounding fluid are due to viscous damping and/or radiation of sound waves propagating in a direction normal to the surface The latter effect will only be significant if the acoustic wavelength becomes equal to or less than a typical dimension of the resonator $[32,33]$ Acoustic radiation can generally be ignored for micromechanical resonators Viscous damping is characterized by two contributions [34-36] One is due to the usual Stokes drag force for a body in uniform motion through a viscous fluid The second (dynamic) part, the so-called shear wave effect, is characternzed by a boundary layer around the vibrating structure and is dependent on the frequency of vibration $\omega$, and further on the density $\rho_{0}$ and viscosity $\eta$ of the fluid medium The quality factor $Q_{\text {viscous }}$ caused by viscous damping can be expressed as [37]

$Q_{\text {viscous }}=\frac{\rho A \omega}{c\left(\frac{R}{\delta\left(\eta, \rho_{0}, \omega\right)}, \eta\right)}$

where $c$ is the coefficient of the dissipative part of the drag force, $R$ represents the relevant linear dımension and $\delta=\left(2 \eta / \rho_{0} \omega\right)^{1 / 2}$ is the characteristic width of the boundary layer If $\delta$ is much larger than the linear dimensions of the resonator, the shear-wave effects can be ignored and $c$ is a given constant, dependent only on $\eta Q_{\text {viscous }}=\rho A \omega / c(\eta)$, stating that in this case the quality factor is linearly proportional to the frequency of vibration The viscous quality factor of a wide beam with a rectangular cross section and for zero apphed axial force can then be expressed as (see also eqn (9))

$Q_{\text {viscous }, n}=\frac{\rho A \omega_{n}}{c(\eta)}=\frac{\alpha_{n}{ }^{2} b}{c(\eta) \sqrt{12}}\left(\frac{h}{l}\right)^{2}\left(\frac{\rho E}{\left(1-v^{2}\right)}\right)^{1 / 2}$

$(\delta \gg R)$

From the above expression it is seen that the viscous quality factor is inversely proportional to the aspect ratio $(l / h)$ of the beam Assuming $c(\eta) \approx 24 \eta$ for a prismatic beam with a rectangular cross section [38], a viscous quality factor in air $\left(\eta=18 \times 10^{5} \mathrm{~N} \mathrm{~s} / \mathrm{m}^{2}\right)$ of approximately $30 \mathrm{is}$ found for the fundamental mode of a clampedclamped silicon beam $1 \mu \mathrm{m}$ wide with an aspect ratio of 100 If shear-wave effects cannot be ignored, the quality factor will be lower and will become directly proportional to $\omega^{1 / 2}$ This dependence has 
been experimentally observed by Lammennk et al [39] and Blom et al [37]

In the discussion above it was assumed that the resonator is isolated in space If the flexurally vibrating resonator is close to another stationary surface, damping forces increase due to a pressure built-up in the intervening space, $1 \mathrm{e}$, the (air) gap $[38,40,41]$ This so-called squeeze-film damping effect becomes significant if the gap spacing approaches or becomes less than the width of the vibrating beam Whereas the viscous quality factor would be of the order of 100-2000 for an isolated beam, it rapidly drops below 1 if the gap spacing is too small This has been experimentally observed by Howe and Muller [41] Squeeze-film damping can be shightly reduced by making ventilation holes in the vibrating beam $[41,42]$ or practically eliminated by placing the beam in an evacuated cavity $[24,27,43]$

The energy coupled into the supporting structure can be minimized by mechanically isolating the resonator from the mount $[1,7]$ An example of a geometry providing a means of decoupling a flexurally vibrating single beam from the support is an isolation system in between the beam and the support This consists of a large mass and an 1solator beam, acting as a soft spring-mass system with a natural frequency much lower than the frequency of the beam and of the support $[44,45]$ In this design, moment and shear reactions are isolated from the support, resulting in a reduction of energy losses The mass has to be large to give it enough rotary inertia to form an efficient clamping edge for the resonating beam A decoupling method for a torsional resonator was reported by Buser and de Roo1] [46] In their structure, a frame was designed around the resonator which itself can vibrate in a torsional mode Again, the aim of the design was to have a high ratio of the resonance frequencies of the resonator and the mountıng frame in order to minımize the energy losses Quality factors in vacuum as high as 600000 were measured for a structure made out of single-crystalline silicon Another way of lowering the energy losses into the support is to use a specific resonator design A well-known example is the double-ended tuning fork (DETF), consisting of two beams vibratıng $180^{\circ}$ out of phase, thereby cancelling moment reactions at the beam roots and resultung in a reduction of energy losses, see Fig 3(a) $[7,47]$ The triple beam structure

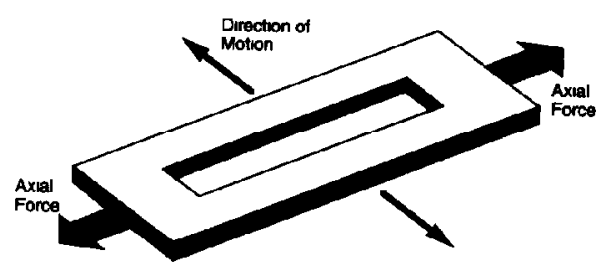

(a)

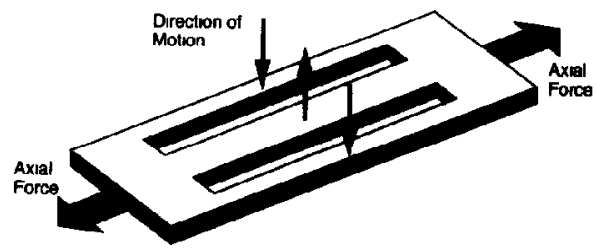

(b)

Fig 3 (a) Double-ended tunıng fork [47], (b) triple beam structure [48]

provides yet another way of cancelling moments and shear forces at the clamped ends, see Fig 3(b) $[48,49]$ It consists of three beams, the middle beam being twice the width of the outer beams The middle beam and the two outer beams vibrate $180^{\circ}$ out of phase, resultıng in the desired cancellation of moments and shear forces This structure is very attractive from a fabricational point of view It can easily be fabricated with planar micromachining technologies and the excitation/detection of the flexural transverse (perpendicular to the substrate) vibrations does not mean any more difficulties than for the single-beam approach This is in contrast to the DETF, which requires inplane excitation/detection schemes Another structure, consisting of a balanced dual-diaphragm, was reported by Stemme and Stemme [42] Here, a balanced torsional mode of vibration is excited, where energy losses into the mount are small because of the stationary centre of mass and because the vibrating element is suspended at the nodal lines, which minimizes the movement of the mount Balanced structures were reviewed by Stemme [5]

Besides the external sources of energy losses described above, there still remains a large number of mechanisms through which vibrational energy can be dissipated within the material that is cyclcally deformed They include magnetic effects 
(magnetoelastic hysteresis), thermal effects (thermoelastic internal friction [50] and atomic reconstructions (dislocations, stress relaxation at grain boundaries) [51] A way of describing viscoelastic material losses or structural damping is by introducing a complex Young's modulus $E^{*}=$ $E(1+1 \gamma)$, where $1=\sqrt{ }-1$ and $\gamma$ is the structural damping factor $[52,53]$ The quality factor $Q_{\mathrm{nt}}$ associated with structural damping is simply given by $Q_{\mathrm{nt}}=1 / \gamma$ Single-crystal materials, such as quartz and single-crystalline silicon, seem to have lower instrinsic losses compared to amorphous or polycrystalline materials, and are therfore more attractive as resonator materials $[9,54]$ However, a lot of work remains in investıgating the damping properties of materials

In describing the arr-pressure dependence of the overall quality factor $Q_{\text {tot }}$, three main pressure regions can be distınguished $[37,38]$ The transition points of these regions depend on the shape and material properties of the resonator and also on the way the resonator is supported In general, viscous damping is the dominatıng mechanism near atmospheric pressure This region can be divided into two sub-regions, depending on the relative width of the boundary layer $\delta$ as discussed before At high pressures and for high frequencies, shear-wave effects dominate and $Q_{\text {tot }}$ will be proportional to $\delta$ and thus to $1 / p^{1 / 2}$, where $p$ is the air pressure At lower pressures and/or frequencies, $Q_{\text {tot }}$ will be independent of $\delta$ and thus independent of $p$ Lowering the pressure even further, the Knudsen gas region is reached and the air no longer acts as a viscous fludd Energy losses are now caused by individual collsions of the gas molecules with the resonator In this region, $Q_{\text {tot }}$ is proportional to $1 / p[37,55]$ At very low pressures $(\mathrm{e} \mathrm{g},<1 \mathrm{~Pa})$ arr damping can be ignored and the quality factor is determined by losses into the support and by the intrinsic losses, makıng $Q_{\text {tot }}$ independent of $p$ Thus, in order to obtain a $Q$-factor as high as possible, vacuum encapsulation of the resonator is necessary

\section{Non-linear (large-amplitude) effects}

In the derivation of eqn (1), small amplitudes of the vibration $w_{\max }$ were assumed If $w_{\max }$ becomes comparable to the radius of gyration,
$r=(I / A)^{1 / 2}$, of the cross section of the beam, the dependence of the axial force on the amplitude of the vibration has to be taken into account, resulting in a non-linear term in eqn (1) [56] If the distance between the ends of the beam is ngidly fixed, a tensle axial force will be developed by the transverse deflection This will result in an increase of the resonance frequencies of the beam and is known in the literature as the 'hard-spring effect' [56-61] To get some idea of the impact of this effect on the natural frequencies, an additional potential energy term is included in Rayleigh's quotient The additional stretching of the midplane of the beam results in a potential energy change $U_{\mathrm{NL}}$ given by

$U_{\mathrm{NL}}=\frac{1}{2} \int_{0}^{l} \frac{E A}{4}\left(\frac{\mathrm{d} w}{\mathrm{~d} x}\right)^{4} \mathrm{~d} x$

Including this term in Rayleigh's quotient results in a modified expression of eqn (6)

$$
\begin{aligned}
\omega_{n}\left(N, w_{\max }\right) & =\omega_{n}(0,0) \\
\times & \left(1+\gamma_{n} \frac{N l^{2}}{12 \hat{E} I}+\beta_{n} \frac{E A}{12 \hat{E} I} w_{\max }^{2}\right)^{1 / 2}
\end{aligned}
$$

where $\omega_{n}(0,0)$ is the natural frequency of mode $n$ for zero axial load and ignoning non-linear effects, $w_{\max }$ is the amplitude of the vibration and $\beta_{n}$ is a constant given by

$\beta_{n}=\frac{3}{\tilde{\phi}_{n, \max }^{2}}\left(\int_{0}^{l}\left(\frac{\mathrm{d} \tilde{\phi}_{n}(x)}{\mathrm{d} x}\right)^{4} \mathrm{~d} x / \int_{0}^{l}\left(\frac{\mathrm{d}^{2} \tilde{\phi}_{n}(x)}{\mathrm{d} x^{2}}\right)^{2} \mathrm{~d} x\right)$

where $\tilde{\phi}_{n \text { max }}$ is the maxumum value of the approximate shape function $\tilde{\phi}_{n}$ For prismatic wide beams with a rectangular cross section and $N=b h E \varepsilon$, eqn (21) can be written as (compare eqn (9))

$$
\begin{aligned}
& \omega_{n}\left(N, w_{\max }\right)=\frac{\alpha_{n}^{2}}{\sqrt{12}}\left(\frac{E}{\rho\left(1-v^{2}\right)}\right)^{1 / 2} \\
& \times \frac{h}{l^{2}}\left[1+\gamma_{n} \varepsilon\left(1-v^{2}\right)\left(\frac{l}{h}\right)^{2}+\beta_{n}\left(1-v^{2}\right)\left(\frac{w_{\max }}{h}\right)^{2}\right]^{1 / 2}
\end{aligned}
$$

Note that the large-amplitude effect requires a (slight) correction of the expressions of the gauge factors given previously 
The dependence of the resonance frequency on the amplitude of vibration given by eqn (23) is similar in form to the frequency dependence of a simple spring-mass system with a restoring force having a cubic dependence on the vibration amplitude An estimate for the coefficients $\beta_{1}$ and $\beta_{2}$ of the fundamental mode and first harmonic, respectively, can be found by substituting the mode shapes for zero axial force into eqn (22) This yields $\beta_{1}=0528$ and $\beta_{2}=1228$ for a prismatic clamped-clamped beam with a rectangular cross section The coefficient $\beta_{n}$ depends on the edge conditions of the beam, e g, for simply supported edges $\beta_{n}$ will be higher In the case of movable axial end supports, the hardening effect will be smaller and can even revert to a softening effect for beams with a sufficiently small aspect ratio $l / h$ [57] The dependence of the resonance frequency on the vibrational amplitude of the fundamental mode of a rigidly clamped-clamped beam, together with a typical large-amplitude forced response plot, is shown in Fig 4 This Figure also indicates the effect of the magnitude of the driving force on the response plot [61] If the magnitude of the driving force exceeds a critical value $F_{\text {crit }}$, the amplitude becomes three-yalued within a range of frequencies This frequency interval defines the region of hysteresis, with two stable points, one at a large amplitude and the other at a small amplitude To avold hysteresis, the

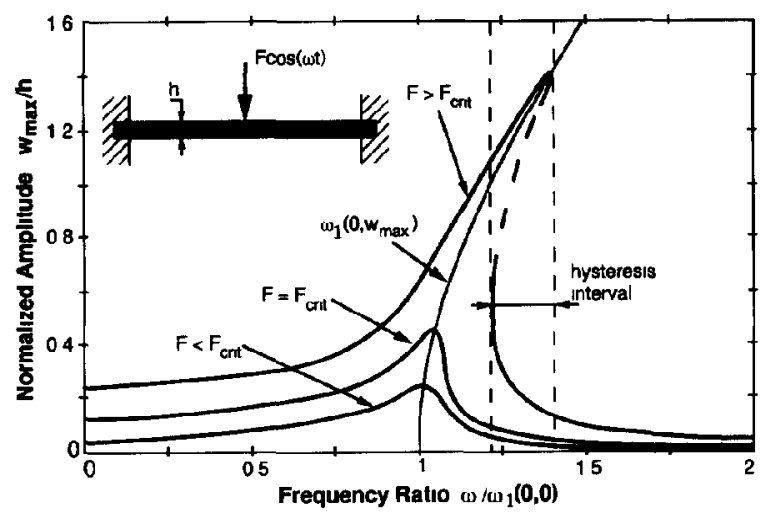

Fig 4 Forced response plots, showing the normalized amplitude vs the normalized frequency for a clamped-clamped beam with a rectangular cross section, illustrating the effect of a large vibrational amplitude If the magnitude $F$ of the excitation force exceeds a critical value $F_{\text {crit }}$, the amplitude becomes three-valued for a particular frequency interval The dashed part of the curve in this interval indicates unstable points [61] magnitude of the driving force should be smaller than the critical load It can be shown that the critical load is inversely proportional to $Q^{3 / 2}$, where $Q$ is the quality factor of the resonator [61] At the critical load, the amplitude of vibration is defined as the critical amplitude $w_{\max c r u}$, being inversely proportional to $Q^{1 / 2}$ Considering a clamped-clamped beam to behave as a simple spring-mass system with a restoring force having a cubic dependence on the amplitude, it can be shown [61] that the critical amplitude can be approximated by

$w_{\text {max crit }} / h \approx\left[2 /\left(Q \beta_{n}\left(1-v^{2}\right)\right)\right]^{1 / 2}$

Hence, even though a high $Q$ has several advantages as indicated in the previous Section, it enhances the chance of hysteresis occurring

Noise or other instabilities of the vibrational amplitude will limit the ultımate frequency resolution or stability of the gauge Any frequency change caused by an amplitude change must be small compared to the minimum frequency change one wishes to resolve It can be derived from eqns (23) and (12) that a condition, which defines an upper limit for the variations $\Delta w_{\max }$ in the amplitude, is given by

$$
\begin{aligned}
\left(\frac{\Delta w_{\max }}{w_{\max }}\right) \ll\left(\frac{\gamma_{n}}{2 \beta_{n} G_{\text {sn }}}\right)\left(\frac{l}{w_{\max }}\right)^{2}\left(\frac{\Delta \omega}{\omega}\right)_{\min } & \left(w_{\max }<w_{\max \text { cnt }}\right)
\end{aligned}
$$

where $(\Delta \omega / \omega)_{\min }$ is the minimum resolution required For a clamped-clamped beam with an aspect ratio $l / h=200, l / w_{\max }=10^{5}$, zero residual strain $\left(\varepsilon_{0}=0\right)$ and a minimum frequency resolution of $10^{-6}$, eqn (24) demands a relative variation of the maximum amplitude much smaller than 05 If the beam thickness $h=1 \mu \mathrm{m}$, this means that $w_{\max }=2 \mathrm{~nm}$ and $\Delta w_{\max } \leqslant 05 \mathrm{~nm}$ The critical amplitude in this case is approximately equal to $20 \mathrm{~nm}$ for $Q=10000$

\section{Excitation and detection of the vibration}

To measure the resonance frequency of a vibrating beam, it must first be excited into vibration and subsequently the vibrational motion must be detected Mathematically, the driving load $q(x, t)$ used to excite the resonator can be accounted for in the inhomogeneous part of the differential equation of motion, as indicated by eqn (1) In 


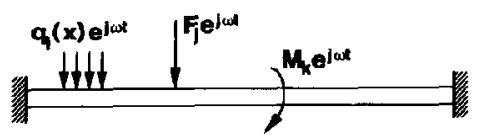

Fig 5 Schematic representation of excitation loads

general, for flexurally vibratıng structures the load $q(x, t)$ represents (harmonically varying) bending moments or transverse forces

$$
\begin{aligned}
q(x, t)= & q(x) \exp (1 \omega t)=\left[\sum_{i} q_{l}(x)+\sum_{\jmath} F_{\jmath} \delta\left(x-x_{\jmath}\right)\right. \\
& \left.+\sum_{k} M_{k} \delta_{-1}\left(x-x_{k}\right)\right] \exp (1 \omega t)
\end{aligned}
$$

where $q_{i}(x)$ is a distributed force per unit length, $F_{J}$ is a point force applied at $x=x_{j}, M_{k}$ is a point moment applied at $x=x_{k}, \omega$ is the frequency of excitation and $\delta_{-1}$ is the derivative of the Dirac function (see also Fig 5)

An expression for the overall response can be obtained from a modal analysis [62-64] The distribution of the driving load along the beam length determines the efficiency of excitation of a particular mode of vibration For instance, if the driving load is symmetric with respect to the centre of the beam, it is (theoretically) impossible to excite an anti-symmetric mode, e $g$, the first harmonic $(n=2)$ A measure for the efficiency of excitation of a particular mode is the generalized load $P_{n}$, given by the inner product of the shape function $\phi_{n}(x)$ of mode $n$ and of the driving load $q(x)$ [64]

$P_{n} \equiv \int_{0}^{l} q(x) \phi_{n}(x) \mathrm{d} x$

A large value for $P_{n}$ implies a large contribution of mode $n$ to the overall response of the resonator

Several excitation/detection schemes have been described in the literature

electrostatic excitation/capacitive detection [ 21 , $25,41,42,65-67]$

magnetic excitation/magnetic detection $[19,24$, 68]

piezoelectrıc/piezoelectrıc $[14,26,69,70]$

electrothermal/piezoresistive $[49,71-74]$

optothermal/optical [23, 75-82]

dielectric/capacitıve [83]
For the first two methods the driving load can be modelled as a distributed transverse force $q_{t}(x)$ and the remaining four methods are modelled as a number of point moments $M_{k} \delta_{-1}\left(x-x_{k}\right)$ Since a discussion of the various means of excitation and detection has been given in the recent literature $[5,79,84]$, only a bref summary will be given here

In the case of electrostatic excitation, the driving load is simply the attractive force between the two plates or electrodes of a capacitor One electrode is formed by (a part of) the beam and the other by a (stationary) surface located at a close distance from the beam Capacitive detection is based on the fact that an a c current will flow through a $\mathrm{d} c$-biased capacitor if the distance between the capacitor plates, and therefore also the capacitance, fluctuates This scheme is very attractive from a technological point of view, fabrication of micromechanical resonators and integration with electronics is relatively easy $[41,66,67]$ However, if the electrical feedthrough and/or parasitic loads are too large, these effects will obscure the detection signal of the mechanical resonance As a consequence, on-chip buffering and/or amplification is generally necessary Furthermore, for proper operation, a d c polarization voltage is required This voltage will reduce the dynamic stiffness of the structure and will therefore result in a lowering of the resonance frequency $[65,85]$ Also, instability will occur if the polarization voltage exceeds the so-called pull-in voltage $[65,85]$ For precision measurements, the dependence of the resonance frequency on the polarization voltage and the instability problem require very stable voltages and amplitudes of vibration

The Lorentz force experienced by a currentcarrying wire in the presence of a magnetic field forms the driving force for a magnetically excited resonator Due to a change in area of the current loop, the magnetic flux passing through the loop will change if the beam vibrates This will induce a voltage in the loop, providing the detection signal Fabrication is relatively simple, but problems arise with packaging $A$ magnet needs to be positioned close to the resonator Another way to develop the static magnetic field is by means of an electrical current flowing through a wire (or coil) that is in close proximity to the resonator, e $g$, a design employing a double-ended tunıng 
fork [68] Problems arise with heat generation, resulting in a temperature difference between the beam and the support, which will induce compressive axial forces and thus results in a lowering of the resonance frequency $[13,73]$

Piezoelectric excitation and piezoelectric detection are based on the inverse piezoelectric effect and the direct piezoelectric effect, respectively [86] The inverse prezoelectric effect manifests itself by a mechanical deformation in the material subjected to an electric field If the prezoelement is rigidly fixed on top of the beam, a bending moment will be developed which is used to excite the beam Conversely, through the direct piezoelectric effect a mechanical stress or strain will generate a dielectric displacement in the material, which can be detected as an electric current in an external circuit This method of excitation/detection has been widely used for quartz resonators, since quartz itself is piezoelectric [7] Thin films of piezoelectric materials such as zinc oxide $(\mathrm{ZnO})$ or aluminium nitride (AlN) are very attractive for use in sllicon-based resonators $\mathrm{ZnO}$ has been investigated extensively for applications as an actuation material [87-91] Due to its strong prezoelectric coupling efficiency, it is a very attractive material for excitation and detection of the vibrational motion of a resonator $\mathrm{A}$ problem, however, is created because of the high $d \mathrm{c}$ conductivity, which prevents the build-up of an electric field Applications at low frequencies $(<1 \mathrm{MHz})$ therefore require special configurations, such as the use of insulating layers or a depleted MOS-like structure [90], which make the fabrication process more complicated and the composite resonator more susceptible to temperature fluctuations as a result of differential thermal expansion effects Furthermore, $\mathrm{ZnO}$ is not an IC-compatible material and special precautions such as encapsulation of the $\mathrm{ZnO}$ layer in silicon nitride layers [92] are necessary to avold zinc contamination and to protect the $\mathrm{ZnO}$ layer against the different etchants used Also, a lot of effort is necessary to study the reproducibility and the effects of heat treatment, humidity and deposition conditions on the mechanical and electrical properties of the $\mathrm{ZnO}$ film

Electrothermal excitation is based on the thermal expansion of a resistive material due to heat generation by an electrical current If the resistor is located in the upper fibres of the beam, a temperature gradient in the thickness direction will develop This in turn creates a bending moment, which is used to excite the beam The motion is detected by piezoresistors, made of doped polycrystalline silicon for example This method is very attractive from a technological point of view Standard IC processing technologies can be used to fabricate the resonator An inherent problem is the static heat generation causing compressive axial forces, which will affect the resonance frequency $[13,73]$ For precision measurements this requires a good control of the heat flow to the surroundings

The basic principle of optothermal excitation is the same as for electrothermal excitation The difference is the heat source, which is now formed by the absorption of light by bare slicon or an absorbing layer, e g, aluminium [93] Several techniques are used for optical detection, such as intensity modulation by means of a shutter controlled by the resonator [81], use of an optical proximity or displacement sensor [94], or interferometric techniques $[23,58,78,80]$ Optical sensors are very attractive for applications where there is no reliable electrical solution, such as under extreme environmental or hazardous conditions Fabrication of the resonator is relatively simple, but the integration with the optical (fibre) system makes the realization more complicated Further, there is a frequency dependence on the optical drive power as a result of thermally induced axial forces $[73,95]$

Dielectric excitation is based on the lateral deformation of a dielectric thin film, sandwiched between a top and bottom electrode, due to an electrostatic force arising if a voltage is applied across the electrodes The lateral deformation will cause bending moments that are used to drive the structure The detection is capacitive, based on the change of the capacitance of a dielectric capacitor if the dielectric is deformed So far, the method seems promising, but the signals appear to be extremely small Only if materials with a very high permittivity, such as PZT, having a reported permittivity as large as 2500 for a thin film [96], are used is this method interesting for future applicat1ons

It is clear that none of the excitation/detection methods described above is perfect They all have certain advantages and disadvantages The choice of a particular method is determined by several 
critena first of all, the kınd and number of materıals that are required for fabrication In this respect, considerations concerning aging of material propertıes, fatıgue, yıeld strength, stress relaxation, etc, and differential thermal expansion effects are important A homogeneous structure, preferably consisting of a single-crystallıne material, seems to be ideal Another relevant aspect is the signalto-noise ratio $\mathrm{A}$ big problem is caused by noise and other interference signals (e $g$, electrical feed-through), which can obscure the mechanical resonance This also requires special attention to the overall design of the structure, including shielding, minımization of parasitic loads, on-chip electronics for buffering, etc An efficient transduction mechanism, e $\mathrm{g}$, using $\mathrm{ZnO}$, is preferred to obtain a large signal level Another constraint is formed by the complexity of the fabrication process with respect to cost, yield and through-put, and further by the technology that is avalable, or whether it can be used in an IC environment or not

\section{Fabrication technology}

The technology described in this Section refers to the micromachining of silicon, silicon-based materials, metals and special transducer materials such as $\mathrm{ZnO} A$ global overview will be given and for processing detalls, reference is made to the literature

Several technologies have been developed over the past three decades to fabricate micromechanıcal resonators In general, two main technologies can be distınguished bulk micromachınıng [9799] and surface micromachining [100-102] Combinations of both have also been used

In the case of bulk machining, a prece of silicon is sculptured into a three-dimensional structure usıng sophisticated etching techniques such as anisotropic etching [103-107], high boron etch stops [105, 108], electrochemical etching [109-114] or HF anodic etching [115, 116] Examples of resonating structures built this way are resonating pressure sensors $[21,23,28,29,72,81,94]$, a resonatıng force sensor $[14,26]$, resonatıng accelerometers $[49,80,117]$, a resonating mass-flow sensor [118, 119] and a vibration sensor [120]

Surface micromachining is generally associated with the deposition of thin films and sacrificial layer etching techniques [102, 121] The first prototype of a resonator fabricated this way was demonstrated by Nathanson et al in 1967 [65] They used metal films for both the construction material and the sacrificial layer More recently, 'construction material/sacrificial layer' combinations of polysilicon/ oxıde $[41,43,66,122,123,124]$, polysilicon/nitride [124], nitride/(poly)silıcon [118, 119, 125-127], oxide/silicon [128] and polyımide/aluminium [129] have been used Prototypes of resonating structures include a resonant vapour sensor [41], a resonatıng mass-flow sensor [118], a resonant force sensor $[25,60]$, a resonating accelerometer $[117]$ and resonatıng polysilicon microbridges [41, 43, 66, 123]

As mentioned before, resonant sensors are very attractive in the precision measurement field However, in order to exploit the advantageous properties, unwanted disturbances have to be elıminated and a high $Q$-factor must be obtained This requires vacuum encapsulation An elegant way of accomplishing this was first demonstrated by Ikeda et al in 1988 [24, 130] Figure 6 shows the basic structure of a differential pressure sensor using a sealed resonator as the strain-sensing element This new concept requires an extended definition of the gauge The term resonant force/strain gauge not only includes the vibrating element itself, but also the evacuated cavity and the shell surrounding the cavity The shell forms an integral part of a resonant force gauge

The fabrication process of sealed resonators as described by Ikeda et al is based on selective epitaxial growth of boron-doped single-crystalline silicon [131], high boron etch stops and selective electrochemical anısotropic etching Very heavily boron-doped $\left(\mathrm{p}^{++}\right)$silicon layers are used as the construction material and heavily boron-doped $\left(\mathrm{p}^{+}\right)$silicon layers as the sacrificial layer The $\mathrm{p}^{++}$ layers are not attacked by the anısotropic etchant

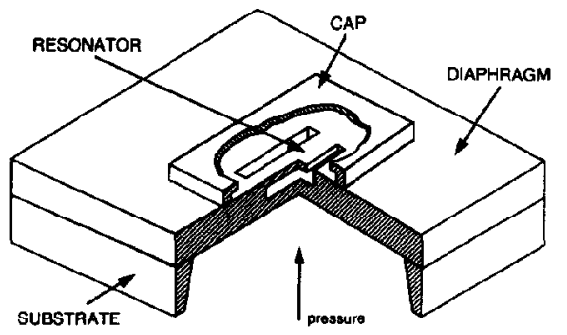

Fig 6 Example of a mechanical sensor consistıng of a diaphragm with an encapsulated bult-in resonator that can be used as a differential pressure sensor 


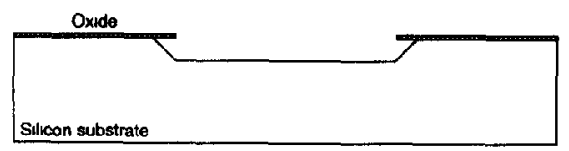

(a)

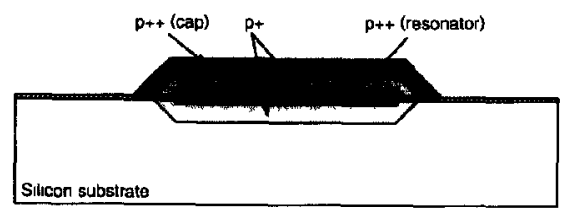

(b)

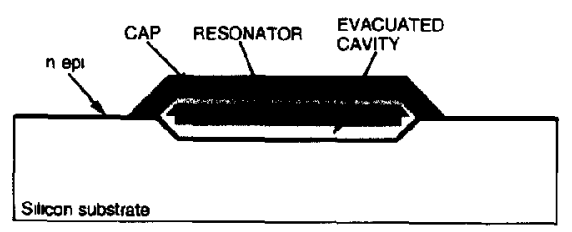

(c)

Fig 7 Fabrication process of sealed resonant force gauges using selective epitaxy [130] (a) After oxidation, patterning and $\mathrm{HCl}$ etching of silicon, (b) after subsequent selective epitaxial growth of $\mathrm{p}^{+}, \mathrm{p}^{++}, \mathrm{p}^{+}$and $\mathrm{p}^{++}$silicon, (c) after removing the oxide, selective etching of $\mathrm{p}^{+}$slicon, reactive sealing with $\mathrm{n}$-ept and annealing in $\mathbf{N}_{2}$

(a mixture of hydrazine and water) due to the high boron concentration [108] The n-type slicon substrate is protected from the etchant through electrochemical passivation The cavity is sealed by closing off the etch channels with n-epi Subsequent high-temperature annealing in a nitrogen atmosphere produces a vacuum cavity $(<1 \mathrm{mTorr})$ by out-diffusion of the residual hydrogen through the silicon cavity walls The basic steps of the process are illustrated in Fig $7(a)-(c)$

An alternative way of fabricating sealed resonators has been described by Guckel et al [43] Their process is based on sacrificial layer etching and reactive sealing techniques [132] In this way a hermetically sealed cavity can be formed with a low residual pressure, as indicated by the obtained quality factors of around 35000 Fine-grained tensile polysilicon, grown using low-pressure chemical vapour deposition (LPCVD) [133, 134], is used as a construction material and silicon oxide and/or nitride can be used as a sacrificial layer The

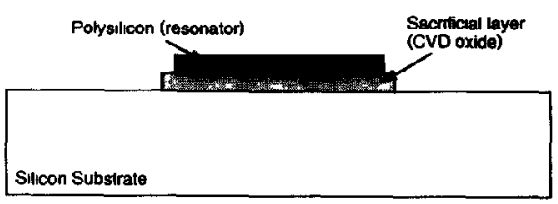

(a)

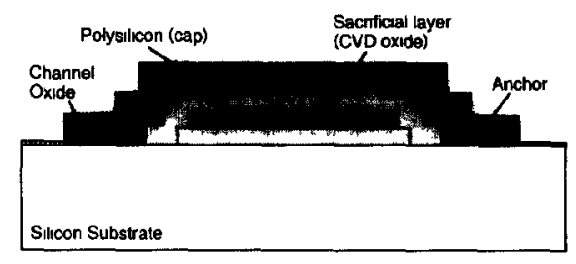

(b)

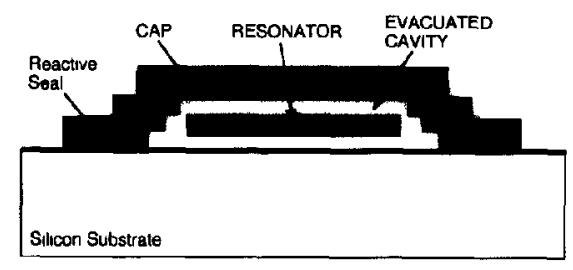

(c)

Fig 8 Fabrication process of sealed resonant force gauges using LPCVD polysilicon [43] (a) After deposition and patterning of the first sacrificial layer (CVD or thermal oxide) and the first polysilicon layer, (b) after deposition and patterning of the second sacrificial layer (CVD oxide or nitride), thin thermal oxide for the etch channels and the second polysilicon layer, (c) after the sacrificial layer etch in $\mathrm{HF}$ and reactive sealing with polysilicon or silicon nitride

sacrificial etchant used is hydrofluoric acid 'Sticking' of the resonator and the sealing cap to the substrate is avoided by freeze-sublimation procedures [124] The basic steps for the formation of sealed polysilicon resonators are schematically shown in Fig 8

A third way of fabricating sealed resonators [135] is based on HF anodic etching $[115,116]$ and silicon fusion bonding [136] The results are preliminary but very encouraging

In deciding which technology to use for the fabrication of sealed resonators, several aspects are worth considering In the case of selective epitaxy and HF anodic etching, single-crystalline silicon is used as the resonator material It is expected that a single-crystalline material is more 
suitable than polycrystalline materials due to the superior material properties with respect to aging, drift, hysteresis, fatıgue, creep, yielding, etc , of the former A definite statement, however, cannot be made at this point since the study of the material properties of polysilicon is still in a preliminary stage Selective epitaxy seems to be more complcated and less flexible For instance, the sealing cap always closely surrounds the resonator This precludes the sealing of more than one resonator in a single cavity, e $g$, as proposed for a differential design for common-mode rejection purposes [137] In addition, as a result of the high deposition rate $(300 \mathrm{~nm} / \mathrm{min})$ of epitaxially grown silıcon, it will be difficult to realize very thin $(<1 \mu \mathrm{m})$ resonators in an accurately controlled and reproducible way For very thin resonators, LPCVD polysilicon (deposition rate of the order of $7 \mathrm{~nm} /$ min) seems to be the best candidate On the other hand, the low deposition rate for polysilicon means long deposition times, which makes this technology less attractive If the resonator thickness exceeds 2-3 $\mu \mathrm{m}$, LPCVD polysilicon is no longer practical

It is pointed out here that in the process descriptions given above, no special attention is paid to the excitation/detection mechanism used Ikeda's resonator is driven magnetically and no additional processing on the resonator is required, since the $\mathrm{p}^{++}$resonator is already conductive enough Guckel's resonator is dnven electrothermally or electrostatically and detection is done peizoresistively This requires additional processing on the resonator to form the polyresistors and the electrodes This can be done in a convenient way by means of local implantation of impurities, e $g$, boron The fabrication of a piezoelectrically driven resonator, on the other hand, creates new challenges to the process engineer $A$ question that arises is how subsequent heat treatments affect the properties of the piezoelectric layer This might exclude epitaxial growth of silicon, since this is done at relatively high temperatures (1000$1150^{\circ} \mathrm{C}$ ) Also, the piezoelectric layer should either be resistant to the sacrificial layer etchant, or it should be protected against the etchant by encapsulating the piezomaterial in a passivation layer

Another relevant aspect is the final stress state of the (composite) resonator caused by the residual stresses in the applied materials In general, it is preferred to have the resonator under small tension This minimizes the chance of buckling and allows long beams to be fabricated A large tension is not attractive, since this will lower the gauge factor and thus the sensitivity of the device, see Fig 2

\section{Design aspects and performance issues}

The sensitivity of a resonant force/strain gauge to an applied (mechanical) load depends on the gauge factor of the resonator Large gauge factors require slender beams with a low residual strain

In a sensor system, the resonant force gauge will be the frequency-determining building block of an electronic oscillator As indicated by eqn (24), automatic gain control (AGC) is necessary to mınımıze error readıngs due to a variable amplitude of vibration Improved behaviour of a feedback oscillator as a result of AGC has been experimentally demonstrated by Ikeda et al [59]

Unwanted frequency shifts are not only caused by spreads in the vibrational amplitude, but can also be caused by a variety of physical and chemccal loads, e g, mass loading due to surrounding fluid, temperature, humidity, vapour adsorption, dust, etc Most of these disturbing loads can be eliminated by isolating the gauge from its surroundings, eg, through vacuum encapsulation Temperature very often remains as a major source of errors Material properties such as Young's modulus and the resonator dimensions are all temperature dependent and, as a result, a temperature change will induce a shift of the resonance frequency Moreover, differential thermal expansion effects within the composite resonator or between the sensor chip and the mount can strongly degrade the performance of the device Solutions to this problem are found in electronic temperature compensation (requiring an on-chip temperature sensor), accurate temperature regulation of the sensor environment and/or by employing a differential resonator design [137] Other common-mode errors that are suppressed in a differential design are variations in the reference clock frequency, aging of material properties, even-order non-linearity effects and, last but not least, mountıng or package-ınduced stresses A further reduction of mounting strains is achieved 
If stress-free assembly technıques [138] or mechan1cal decoupling zones [139] are used

Factors that might limit the resolution are the excitation/detection scheme used and, of course, the noise in the system [140] If the resonator is regarded as a simple harmonic oscillator with an angular frequency of resonance $\omega_{0}$, and if the feedback oscillator is locked at the frequency where the phase shift is $\pi / 2$ radians, $1 \mathrm{e}$, at $\omega=\omega_{0}$, the minımum relative frequency resolution is given by

\section{$(\Delta \omega / \omega)_{\min }=(1 / 2 Q) \Delta \phi_{\min }$}

where $Q$ is the mechanical quality factor of the resonator and $\Delta \phi_{\min }$ the minımum phase shift that can be detected by the oscillator Hence, the resolution is inversely proportional to the quality factor $Q$ The minımum phase shift that can be resolved is determined by the resolution of the detection mechanism and by the noise in the entire system

As already indicated above, the ultimate resolution of the resonant force gauge is determined by several factors temperature sensitivity and varnaitons, stability of electrical components of the feedback oscillator, stability of the environment and the quality factor of the resonator These factors actually determine the short-term resolution or stability $(\Delta \omega / \omega)_{\mathrm{S} \text {, min }}$, which can be expressed mathematically as

$$
\begin{gathered}
\left(\frac{\Delta \omega}{\omega}\right)_{\mathrm{s} \min }=\max \left[\left(\frac{\Delta w_{\max }}{w_{\max }}\right)_{\min }^{2}\left(\frac{w_{\max }}{l}\right)^{2}\left(\frac{2 \beta_{n} G_{\varepsilon n}}{\gamma_{n}}\right)\right. \\
\frac{1}{2 Q} \Delta \phi_{\min }, G_{T} \Delta T_{\min }, G_{L} \Delta L_{\min },
\end{gathered}
$$

where $\max$ is the 'maximum' function, the first argument between the brackets can be obtained from eqn (24), $G_{T}=(1 / \omega)(\partial \omega / \partial T)$, the relative temperature sensitivity of the gauge and $G_{L}=$ $(1 / \omega)(\partial \omega / \partial L)$, the relative sensitivity of the gauge to any other unwanted load $L$, e g, humidity, $\Delta T_{\min }$ and $\Delta L_{\min }$ are the minımum variations in temperature and other unwanted loads seen by the resonator, respectively The resolution $\Delta p_{\mathrm{min}}$, defined as the smallest change in load, e g, a pressure change, that can be distinguished by the sensor structure ( $\mathrm{e} g$, the pressure sensor as shown in Fig 6) is given by
$\Delta p_{\mathrm{min}}=\left(1 / G_{p}\right)(\Delta \omega / \omega)_{\mathrm{S} \min }$

where $G_{p}=(1 / \omega)(\partial \omega / \partial p)$, the relative frequency sensitivity of the sensor to the applied mechanical load $p$

In speakıng of long-term resolution or stability, aging phenomena, creep and stress relaxation become relevant Long-term drift requires frequent recalibration of the system This generally concerns drift of material properties and it is expected that single-crystalline materials have more stable properties than polycrystalline or amorphous materials Therefore, single-crystalline materials are preferred Also, the intrinsic quality factor of these materials is higher

According to Karrer and Ward [141], the response time is determined by (1) the time the resonator is maintained at the old load, (2) the magnitude of the load change, and (3) the desired degree of stability It is expected that the response time is small compared to the time required for counting the frequency shift, especially in highprecision sensors

Finally, mode interference, or in other words interference of unwanted modes with the desired mode, is a relevant issue For complex resonator shapes, the frequencies of the different modes of vibration can be very close to each other and they all have different sensitivities to the axial load, e $g$, $[49,142]$ The dynamic range or measurement window of the gauge will be limited to the frequency range where modes do not interfere, since only here will the frequency be a singlevalued function of the axial load The best way to increase the dynamic range is to keep the resonator structure simple and, moreover, to design and place the excitation/detection elements in such a way that the unwanted modes are not excited (see also eqn (26)) and/or cannot be detected

\section{Conclusions}

Resonant force gauges are very attractive for precision measurements because of their high sens1tivity, high stability and frequency output Micromachining of the gauges allows batch fabrication to take place, with possible on-chip electronics, manufacturing costs to be reduced and reproducibility to be improved 
To be effectively employed in high-performance sensors, resonant force gauges must be isolated from the environment to elımınate frequency shifts caused by unwanted loads A very promising way of doing this, which might define the direction of future research, is by means of local vacuum encapsulation of the gauge in a batch fabrication process From this point of view the cavity and the enclosing shell form an integral part of the gauge Temperature will always remain as a disturbing load and special attention must be given not only to the force gauge, but also to the design of the entıre sensor chip, including packaging aspects to reduce differential thermal expansion effects

Single-crystalline materials such as single-crystalline silicon and quartz have highly stable properties with low hysteresis and creep, which makes them very suitable for the fabrication of resonant force/strain gauges The potential application of other materials such as thin films of polycrystalline silicon and silicon nitride should be further investigated with respect to stability and repeatability of mechanical properties, because they are very attractive from a micromachining point of view Complex mechanical structures, including sealed resonators, can relatively easily (as compared to quartz and single-crystalline slicon) be fabricated Furthermore, the thin-film/sacrificial layer technology is very flexıble and versatıle Also, more effort must be put into the development of new technologies for micromachıning single-crystallıne silıcon, such as dopant-selective electrochemical etching and HF anodic etching $A$ challenge is formed by the proper selection and implementation of a suitable excitation/detection scheme that has a minimal degrading effect on the resonator performance

The feasibility of silicon resonant force gauges has already been demonstrated by a large number of laboratory prototypes, but as indicated in this paper, a long way still has to be gone to demonstrate their applicability in a real environment

\section{Acknowledgements}

The authors would like to thank Dr Siebe Bouwstra for many fruitful discussions and his valuable comments on the manuscript

\section{References}

1 R M Langdon, Resonator sensors-a review, J Phys E Scl Instrum , 18 (1985) 103-115

2 Th Gast, Sensors with oscillating elements, $J$ Phys $E$ Sct Instrum , 18 (1985) 783-789

$3 \mathrm{R} T$ Howe. Resonant microsensors. Proc 4th Int Conf SoludState Sensors and Actuators (Transducers '87), Tokyo, Japan, June 2-5, 1987, pp 843-848

4 E A Kartsev, Analysis of the status and the prospects for improving sensors that measure parameters of production processes in the manufacture of integrated circuits, Sov Microelectron, 13 (1984) $281-287$

5 G Stemme, Resonant silicon sensors, $J$ Micromechan Microeng , 1 (1991) 113-125

$6 \mathrm{M}$ Elwenspoek, Micromechanical resonant sensors, submitted to Journal A, 32 (1991) 15-22

7 E $P$ Eernisse, $R$ W Ward and $\mathbf{R}$ B Wiggins, Survey of quartz bulk resonator sensor technologies, IEEE Trans Ultrasonics, Ferroclect Freq Control, UFFC-35 (1988) 323-330

8 L D Clayton, E P Eernisse, R W Ward and R B Wiggins, Miniature crystallıne quartz electromechanical structures, Sensors and Actuators, 20 (1989) 17I-177

9 M Dufour, M T Delaye, F Michel, J S Danel, B Diem and $G$ Delapierre, A comparison of micromachıned pressure sensors using quartz or silicon vibratıng beams, Proc 6ih Int Conf Solid-State Sensors and Actuators (Transducers '91), San FrancLsco, CA, USA, June 24-27, 1991, pp 668-671

$10 \mathrm{~S} \mathrm{P}$ Timoshenko, D $\mathrm{H}$ Young and $\mathrm{W}$ Weaver, Vibration Problems in Enguneering, Wiley, New York, 4th edn, 1974, Ch 5

$11 \mathrm{~S}$ Timoshenko, Mathematical determination of the modulus of elastıcity, Mech Eng, 45 (1923) 259-260

12 I H Shames and C L Dym, Energy Methods and Funte Element Methods in Structural Mechanics, McGraw-Hill, New York, 1985, Ch 7

$13 \mathrm{~S}$ Bouwstra and B Geijselaers, On the resonance frequencies of microbndges, Proc 6th Int Conf Solld-State Sensors and Actuators (Transducers '91), San Francksco, CA, USA, June 24-27, 1991, pp 538-542

$14 \mathrm{C} J$ van Mullem, F $\mathrm{R}$ Blom, J H J Fluttman and $M$ Elwenspoek, Piezoelectncally driven slicon beam-force sensor, Sensors and Actuators A, 25-27 (1991) 379-383

$15 \mathrm{R} J$ Roark and $\mathrm{W} C$ Young, Formulas for Stress and Strain, McGraw-Hill, New York, 5th edn, 1982, pp 1881191

$16 \mathrm{~W}$ C Albert, Vibratıng quartz crystal beam accelerometer, Proc 28th ISA Int Instrument Symp, Las Vegas, NV, USA, May 3-6, 1982, pp 33-44

$17 \mathrm{C} \mathrm{S} \mathrm{Kım} \mathrm{and} \mathrm{S} \mathrm{M} \mathrm{Dickinson.} \mathrm{The} \mathrm{flexural} \mathrm{vibration} \mathrm{of}$ slightly curved slender beams subject to axial end displacement, $J$ Sound $V a b, 104$ (1986) 170-175

18 B Geijselaers and $H_{1} T_{1 j}$ deman, The dynamic mechanical charactenstics of a resonating microbndge mass flow sensor, Sensors and Actuators A, 29 (1991) 37-41

19 P R Wyman, A new force to frequency transducer, Digital Instrumentation, IEEE Conf Publ 106 (1973) 117-123

20 M F Belyaev, D D Dorzhiev and L G Etkın, Vibrationfrequency pressure transducer, Instrument Constr (USSR), (10) (1965) $10-13$

$21 \mathrm{~J} C$ Greenwood, Etched sihcon vibrating sensor, $J$ Phys $E$ Scl Instrum, 17 (1984) 650-652

$22 \mathrm{~K}$ Ikeda and $\mathrm{T}$ Watanabe, Pressure sensor using $S_{1}$ resonantbeam strain gauge, Proc SICE '86, Tokyo, Japan, July 23-25, 1986, pp 561-562 
23 K E B Thornton, D Uttamchandanı and B Culshaw, A sensitive optically excited resonator pressure sensor, Sensors and Actuators A, 24 (1990) 15-19

$24 \mathrm{~K}$ Ikeda, H Kuwayama, T Kobayashı, $T$ Watanabe, $T$ Nishikawa and $T$ Yoshida, Sllicon pressure sensor with resonant strain gauge bult into diaphragm, Tech Digest, 7 th Sensor Symp, Tokyo, Japan, 1988, pp 55-58

25 J J Sniegowsk1, H Guckel and T R Christenson, Performance characteristics of second generation polysilicon resonating beam force transducers, Proc IEEE Solld-State Sensors and Actuators Workshop, Hilton Head Island, SC, USA, June 4-7, 1990, pp $9-12$

26 F $R$ Blom, S Bouwstra, J $H$ J Flutman and $M$ Elwenspoek, Resonatung silicon beam force sensor, Sensors and Actuators, 17 (1989) 513-519

27 H A C Tilmans, S Bouwstra, J H J Fluitman and S L Spence, Design considerations for micromechanical sensors using encapsulated built-1n resonant strain gauges, Sensors and Actuators A, 25-27 (1991) 79-86

28 R A Buser, N F de Rool] and L Schultheis, Silicon pressure sensor based on a resonating element, Sensors and Actuators $A$, 25-27 (1991) 717-722

29 K Petersen, F Pourahmadı, J Brown, P Parsons, M Skınner and $J$ Tudor, Resonant beam pressure sensor fabricated with silicon fusion bonding, Proc 6th Int Conf Solid-State Sensors and Actuators (Transducers '91), San Francisco, CA, USA, June 24-27, 1991, pp 664-667

$30 \mathrm{~K}$ Bethe, D Baumgarten and J Frank, Creep of sensor's elastic elements metals versus non-metals, Sensors and Actuators, A21-A23 (1990) 844-849

31 A Prak, F $\mathbf{R}$ Blom, $M$ Elwenspoek and T S J Lammennk, $Q$-factor and frequency shift of resonating slicon diaphragms in air, Sensors and Actuators A, 25-27 (1991) 691-698

$32 \mathrm{~W} K$ Blake, The radiation from free-free beams in air and in water, $J$ Sound $V_{I} b, 33$ (1974) $427-450$

33 R K Jeyapalan and E J Richards, Radiation efficiencies of beams in flexural vibration, $J$ Sound Vibr, 67 (1979) 5567

$34 \mathrm{M}$ Christen, Air and gas damping of quartz tuning forks, Sensors and Actuators, 4 (1983) 555-564

35 T Terasawa, Y Kawamura, $\mathrm{K}$ Sato and $\mathbf{S}$ Tanaka, Pressure dependent dynamic characteristics of minature silicon oscillator, Bull Jpn Soc Prec Engg, 22 (1988) 49-54

36 L D Landau and E M Lifshitz, Flutd Mechanics, Pergamon, Oxford, 2nd edn , 1963, Ch 2

37 F R Blom, S Bouwstra, $M$ Elwenspoek and J H J Fluitman, Dependence of the quality factor of silicon beam resonators on pressure and geometry, $J$ Vac Scl Technol B, in press

38 W E Newell, Miniaturization of tuning forks, Sctence, 161 (1968) 1320-1326

39 T S J Lammerink, $M$ Elwenspoek and J H J Fluttman, Thermal actuation of silicon clamped microbeams, Sensors Mater, 3(2) (1991) in press

$40 \mathrm{~J} \mathrm{~B} \mathrm{Starr,} \mathrm{Squeeze-film} \mathrm{damping} \mathrm{in} \mathrm{solid-state} \mathrm{accelerometers,}$ Proc IEEE Soltd-State Sensors and Actuators Workshop, Hilton Head Island, SC, USA, June 4-7, 1990, pp 44-47

$41 \mathrm{R} T$ Howe and $\mathbf{R}$ S Muller, Resonant-microbridge vapor sensor, IEEE Trans Electron Devices, ED-33 (1986) 499 506

$42 \mathrm{E}$ Stemme and $\mathrm{G}$ Stemme, $\mathrm{A}$ balanced resonant pressure sensor, Sensors and Actuators, A2I-A23 (1990) 336-341

43 H Guckel, J J Sniegowsk1, T R Christenson and F Raissı, The application of fine-grained, tensile polysilicon to mechan1cally resonant transducers, Sensors and Actuators, A21-A23 (1990) 346-351
$44 \mathrm{~W} C$ Albert, Force sensing using quartz. crystal flexure resonators, Proc 38th Ann Frequency Control Symp, 1984, pp 233-239

45 W C Albert, A low cost force sensing crystal resonator applied to weighıng, Proc 42nd Ann Frequency Control Symp, Balttmore, MD, USA, 1-3 June, 1988, pp 78-84

46 R A Buser and N F de Roow, Very high $Q$-factor resonators in monocrystalline silicon, Sensors and Actuators, A21-A23 (1990) 323-327

47 T Ueda, F Kohsaka and E Ogita, Precision force transducers using mechanical resonators, Measurement, 3 (1985) 89-94

48 R G Kirman, A vibrating quartz force sensor, Transducers Tempcon Conf Papers 1983, London, June 14-16, 1983, 24 pp

49 D W Satchell and J C Greenwood, A thermally-excited silicon accelerometer, Sensors and Actuators, 17 (1989) 241245

$50 \mathrm{~T}, \mathrm{~V}$ Roszhart, The effect of thermoelastic internal friction on the $Q$ of micromachined silicon resonators, Proc IEEE SolldState Sensor and Actuator Workshop, Huton Head Island, SC, USA, June 4-7, 1990, pp 13-16

51 A Muszynska, Internal dampling in mechanical systems, in Dynamika Maszyn, Polısh Acad Scı, Ossolıneum, Warsaw, 1974, pp 164-212 (in Polısh)

$52 \mathrm{~W}$ T Thomson, Theory of Vibration with Applications, Prentice-Hall Inc, Englewood Cliffs, NJ, 2nd edn, 1981, pp 74-75

$53 \mathbf{R}$ E D Bishop, The treatment of damping forces in vibration theory, $J R$ Aeronaut $S o c, 59$ (1955) 738-742

54 B Hok and $\mathrm{K}$ Gustafsson, Vibration analysis of micromechan1cal elements, Sensors and Actuators, 8 (1985) 235-243

$55 \mathrm{R} G$ Christian, The theory of oscillating-vane vacuum gauges, Vacuum, 16 (1966) 175-178

$56 \mathrm{~J} G$ Eisley, Nonlinear vibration of beams and rectangular plates, $J$ Appl Math Phys, 15 (1964) 167-175

$57 \mathrm{C}$ Mel and $\mathrm{K}$ Decha-Umphal, A finite element method for non-linear forced vibrations of beams, $J$ Sound $V b b, 102$ (1985) $369-380$

$58 \mathrm{M} \mathrm{V}$ Andres, $\mathrm{K}$ W $\mathrm{H}$ Foulds and $\mathrm{M} \mathrm{J}$ Tudor, Nonlınear vibrations and hysteresis of micromachined silicon resonators designed as frequency-out sensors, Electron Lett, 23 (1987) $952-954$

59 K Ikeda, H Kuwayama, T Kobayash1, T Watanabe, T Nishikawa, $\mathbf{T}$ Yoshida and $\mathbf{K}$ Harada, Study of nonlinear vibration of silicon resonant beam strain gauge, Proc 8th Sensor Symp, Tokyo, Japan, 1989, pp 21-24

60 J D Zook, D W Burns, H Guckel, J J Snıegowskı, R L Engelstad and $\mathrm{Z}$ Feng, Resonant microbeam strain transducers, Proc 6th Int Conf Solud-State Sensors and Actuators (Transducers '91), San Franctsco, CA, USA, June 24-27, 1991, pp $529-532$

61 L D Landau and E M Lifschitz, Lehrbuch der theoretischen Physık-Mechanik, Akademie-Verlag, Berlın, 3rd edn , 1964, pp 101-104

62 L Meirovitch, Elements of Vibration Analysis, McGraw-Hill, New York, 1975, Ch 5

63 J J L M van Vlerken, S Bouwstra, F R Blom, J H J Fluitman and $P$ C Breedveld, Finte-mode bond-graph model of a resonant slicon-beam force sensor, Int J Modeling Simulanon, accepted for publication

$64 \mathrm{H} \mathrm{A} \mathrm{C} \mathrm{Tilmans,} \mathrm{D} \mathrm{J} \mathrm{IJntema} \mathrm{and} \mathrm{J} \mathrm{H} \mathrm{J} \mathrm{Fluitman,} \mathrm{Single}$ element excitation and detection of (micro-) mechanical resonators, Proc 6ih Int Conf Soltd-State Sensors and Actuators (Transducers '9I), San Francisco, CA, USA, Jume 24-27, 1991, pp 533-537

$65 \mathrm{H}$ C Nathanson, W E Newell, R A Wickstrom and J R Davis, $\mathrm{Jr}$, The resonant gate transistor, IEEE Trans Eleciron Devices, ED-14 (1967) 117-133 
$66 \mathrm{M}$ W Putty, S C Chang, R T Howe, A L Robinson and K D Wise, Process integration for active polysilicon resonant microstructures, Sensors and Actuators, 20 (1989) 143-151

$67 \mathrm{C}$ Linder. E Zimmerman and N F de Rooy, Capacitive polysilicon resonator with MOS detection circuit, Sensars and Actuators A, 25-27 (1991) 591-595

68 R A Buser and N F de Rool], Tuning forks in silicon, Proc Micro Electro Mechanical Systems (MEMS '89), Salt Lake City, UT, USA, Feb 1989, pp 126-132

$69 \mathrm{~W} C$ Blanchard, Design of a resonant pressure sensor, Instrum Control Syst, (1972) 35-36

70 J G Smits, $H$ A C Tilmans, $K$ Hoen, $H$ Mulder, $J$ van Vuuren and $\mathbf{G}$ Boom, Resonant diaphragm pressure measurement system with $\mathrm{ZnO}$ on $\mathrm{S} 1$ excitation, Sensors and Actuators, 4 (1983) 565-571

71 R J Wilfinger, P H Bardell and D S Chhabra, The resonistor a frequency selective device utilizing the mechanical resonance of a silicon substrate, IBM $J$ Res Dev , 12 (1968) 113118

72 T S J Lammerink and W Wlodarsk1, Integrated thermally excited resonant diaphragm pressure sensor, Proc 3rd Int Conf Solid-State Sensors and Actuators (Transducers '85), Phladelphia, PA, USA. June 11-14, 1985, pp 97-100

73 T S J Lammerınk, M Elwenspoek, $R$ H van Ouwerkerk, S Bouwstra and $\mathrm{J} \mathrm{H}$ J Fluitman, Performance of thermally excited resonators, Sensors and Actuators, A2I-A23 (1990) 352356

74 M B Othman and A Brunnschweler, Electrothermally excited silicon beam mechanical resonator, Electron Lett, 23 (1987) $728-730$

75 E Dieulesaint, D Royer and C Bonnefoy, Mechanical excitation of a membrane by an optical beam, IEEE Proc 1981 Ultrasonics Symp, 1981, pp 802-805

76 H Wolfelschneider, R Kist, G Knoll, S Ramaknshnan and H Hofflin, Optically excited and interrogated micromechanical sllicon cantilever structure, SPIE, Vol 798, 1987, pp 6166

$77 \mathrm{~W}$ Benecke, A Heuberger, W Riethmuller, U Schnakenberg, H Wofelschneider, R Kist, G Knoll, $S$ Ramaknshnan and $H$ Hofflin, Optically excited mechanical vibrations in micromachined silicon cantilever structures, Proc 4ih Int Conf SolidState Sensors and Actuators (Transducers '87), Tokyo, Japan, June 2-5, 1987, pp 838-842

$78 \mathrm{~S}$ Venkatesh and B Culshaw, Optically activated vibrations in a mıcromachıned silıca structure, Electron Lett, 2I (1985) 315317

79 B Culshaw, Silicon microresonator transducers, SPIE Proc, Vol 1011, 1989, pp 197-202

80 M J Tudor, M V Andres, K W H Foulds and J M Naden, Silicon resonator sensors interrogation techniques and charactenstucs, IEEE Proc, 135 (1988) 364-368

81 T S J Lammerink and S J Gerntsen, Fibre optic sensors based on resonating mechancal structures, SPIE, Vol 798, 1987, pp $67-71$

82 T S J Lammerınk, $M$ Elwenspoek and J H J Fluitman, Optical excitation of micromechanical resonators, Proc IEEE Micro Electro Mechanical Systems, Nara, Japan, Jan 30-Feb 2, 1991, pp 160-165

83 S Bouwstra, F $R$ Blom, T S J Lammerınk, H IJntema, P Schrap, J H J Fluitman and M Elwenspoek, Excitation and detection of vibrations of micromechanical structures using a dielectric thin film, Sensors and Actuators, 17 (1989) 219223

84 M Elwenspoek, F $R$ Blom, S Bouwstra, T S J Lammerınk, F C M van de Pol, $H$ A C Tilmans, Th J A Popma and J H J Flustman, Transduction mechanisms and their applications in micro-mechanical devices, Proc Micro Electro Mechanical Systems (MEMS '89), Salt Lake Cuty, UT, USA, Feb 1989, pp $126-132$

85 D J Untema and H A C Tilmans, Static and dynamic aspects of an air-gap capacitor, Sensors and Actuators, submitted

86 D A Berlincourt, D R Curren and H J Jaffe, Piezoelectnc and piezomagnetic materials and their function in transducers, in W P Mason (ed), Physical Acoustics, Vol IA, Academic Press, New York, 1964, pp 169-270

$87 \mathrm{~T}$ Shosaka and A Kawabata, Low-frequency piezoelectric transducer applications of ZnO film, Appl Phys Lett, 25(1974) 10

88 F S Hickernell, Zinc oxıde films for acoustoelectric device applications, IEEE Trans Sonics Ultrasones, $S U$-32 (1985) 621629

89 D L Polla and R S Muller, Zinc oxıde thin films for integrated sensor applications, Tech Digest, IEEE Solid-State Sensors Workshop, Hulton Head Island, SC, USA, June 6-9, 1986

90 F R Blom, D J IJntema, F C M van de Pol, M Elwenspoek, J H J Flutman and Th J A Popma, Then-film $\mathrm{ZnO}$ as micromechanical actuator at low frequencies, Sensors and Actuators, A21-A23 (1990) 226-228

$91 \mathrm{~W}$ Tjhen, T Tamagawa, C -P Ye, C-C Hsueh, P Schiller and D L Polla, Properties of prezoelectnc thin films for micromechanical devices and systems, Proc IEEE Micro Electro Mechanical Systems, Nara, Japan, Jan 30-Feb 2, 1991, pp 114-119

92 M J Vellekoop, C C G Visser, P M Sarro and A Venema, Compatibility of zinc oxide with silicon IC processing, Sensors and Actuators, A21-A23 (1990) 1027-1030

93 D Walsh and B Culshaw, Optıcally activated sthcon microresonator transducers an assessment of material properties, Sensors and Actuators $A, 25-27$ (1991) 711-716

$94 \mathrm{~J}$ G Smits, H A C Tilmans and $\mathrm{T} S \mathrm{~J}$ Lammerink, Frequency dependence of resonant diaphragm pressure sensor, Proc 3rd Int Conf Soldd-State Sensors and Actuators (Transducers '85), Philadelphia, PA, USA, June 11-14, 1985, pp 9396

95 D Walsh, L M Zhang, D Uttamchandan and B Culshaw, Experimental and theoretical analysis of the frequency response of a silicon microresonator to variations in incident optical power, Tech Digest MME'90, 2nd Workshop on Micromachining, Micromechanics and Microsystems, Berlin, Germany, Nov 26-27, 1990

$96 \mathrm{M}$ Böffgen and $\mathrm{H}$ Schmitt, Sputtering of thın films of $\mathrm{Pb}(\mathrm{ZrT})_{1} \mathrm{O}_{3}$, Ferroelectrics, 108 (1990) 15-20

$97 \mathrm{~K}$ E Petersen, Silicon as a mechanıcal material, Proc IEEE, 70 (1982) $420-457$

$98 \mathrm{H}$ Seidel, The mechanısm of anısotropic sllicon etching and its relevance for micromaching, Proc 4th Int Conf Solud-State Sensors and Actuators (Tranducers '87), Tokyo, Japan, June 2-5, 1987, pp 120-125

99 B Hök, Micromechanıcs and micromachınıng of semiconductor sensors, Acta Polytech Electr Eng Ser, E163 (1988) 65-84

$100 \mathrm{R} \mathrm{S}$ Muller, Technologies and matenals for microsensors and actuators, Tech Digest, 7th Sensor Symp, Tokyo, Japan, 1988, pp 7-11

$101 \mathrm{H}$ Guckel and D W Burns, A technology for integrated transducers, Proc 3rd Int Conf Soltd-State Sensors and Actuators (Transducers '85), Philadelpha, PA, USA, June 11-14, 1985, pp 90-92

$102 \mathrm{R} T$ Howe, Surface micromachining for microsensors and microactuators, J Vac Sct Technol B, 6(6) (1988) 18091813

$103 \mathrm{~K}$ E Bean, Anisotropic etching of silicon, IEEE Trans Electron Devices, ED-25 (1978) 1185-1193 
104 E Bassous, Fabrication of novel three-dimensional structures by the antsotropic etching of (100) and (110) silicon, IEEE Trans Electron Devices, ED-25 (1978) 1178-1185

$105 \mathrm{H}$ Seidel and L Csepreg,, Three-dimensıonal structuring of slicon for sensor applications, Sensors and Actuators, 4 (1983) 455-463

106 O Tabata, R Asahı, H Funabashı and S Sugıyama, Anisotropic etching of silicon in $\left(\mathrm{CH}_{3}\right)_{4} \mathrm{NOH}$ solutions, Proc 6th Int Conf Soldd-State Sensors and Actuators (Transducers '91), San Francisco, CA, USA, June 24-27, 1991, pp 811814

107 U Schnakenberg, W Benecke and P Lange, TMAHW etchants for silicon micromachining, Proc 6th Int Conf Sold-State Sensors and Actuators (Transducers '91), San Francisco, CA, USA, June 24-27, 1992, pp 815-818

$108 \mathrm{H} \mathrm{A}$ Waggener, Electrochemically controlled thinning of silhcon, Bell Syst Tech $J, 50$ (1970) 473-475

109 P M Sarro and A W van Herwaarden, Si cantilever etching for sensor applications, $J$ Electrochem Soc, 133 (1986) 1724 1729

110 B Kloeck, S D Collıns, N F de Roolj and R L Smith, Study of electrochemical etch-stop for high precision thickness control of silicon membranes, IEEE Trans Electron Devices, ED-36 (1989) 663-669

111 Y Linden, L Tenerz, J Tiren and B Hok, Fabrication of three-dimensional silicon structures by means of dopant-selective etching, Sensors and Actuators, 16 (1989) 67-82

$112 \mathrm{H}$ Seidel, The mechanism of anisotropic, electrochemical silicon etching in alkalıne solutions, Proc IEEE Soldd-State Sensor and Actuator Workshop, Hilton Head Island, SC, USA, June 4-7, 1990 , pp 86-91

$113 \mathrm{~V}$ M McNell, S S Wang, K-Y Ng and M A Schmidt, An investigation of the electrochemical etching of $(100)$ silicon in $\mathrm{CsOH}$ and $\mathrm{KOH}$, Proc IEEE Solzd-State Sensor and Actuator Workshop, Htlton Head Island, SC, USA, June 4-7, 1990, pp 92-97

114 S S Wang, V M McNell and M A Schmıdt, Selectıve etching of n-type silicon using pulsed potential anodization, Proc 6th Int Conf Solzd-State Sensors and Actuators (Transducers '91), San Francisco, CA, USA, June 24-27, 1991, pp 819-822

115 C J M Eıjkel, J Branebjerg, M Elwenspoek and F C $\mathbf{M}$ van de Pol, A new technology for micromachining of silicon dopant selective HF anodic etching for the realization of low-doped monocrystalline sihcon structure, IEEE Electron Device Lett , II (1990) $588-589$

116 J Branebjerg, C J M Eijkel, J G E Gardenıers and F C M van de Pol, Dopant selective HF anodic etching of silicon, Proc IEEE Micro Electro Mechanical System, Nara, Japan, Jan 30Feb 2, 1991, pp 221-226

117 S C Chang, M W Putty, D B Hicks, C H Li and R T Howe, Resonant-bridge two-axis microaccelerometer, Sensors and Actuators, A21-A23 (1990) 342-345

118 S Bouwstra, R Legtenberg, H A C Tilmans and M Elwenspoek, Resonating microbridge mass flow sensor, Sensors and Actuators, A21-A23 (1990) 332-335

$119 \mathrm{R}$ Legtenberg, S Bouwstra and J H J Fluitman, Resonating microbridge mass flow sensor with low-temperature glassbonded cap wafer, Sensors and Actuators A, 25-27 (1991) 723 727

$120 \mathrm{~W}$ Benecke, L Csepregi, A Heuberger, K Kuhl and H Seidel, A frequency-selective piezoresistive slicon vibration sensor, Proc 3rd Int Conf Solld-State Sensors and Actwators (Transducers '85), Philadelphia, PA, USA, 1985, pp 103-108

$121 \mathrm{D} \mathrm{W}$ Burns and $\mathrm{H}$ Guckel, Thun films for micromechanical sensors, J Vac Sct Technol A, 8(4) (1990) 3606-3613
122 M Farooqui and A G R Evans, Polysilicon microstructures, Proc IEEE Micro Electro Mechanical Systems, Nara, Japan, Jan 30-Feb 2, 199I, pp 187-191

$123 \mathrm{C}$ Linder and N F de Rooly, Investigations on free-standing polysilicon beams in vew of their applications as transducers, Sensors and Actuators, A21-A23 (1990) 1053-1059

124 H Guckel, J J Sniegowskı, T R Christenson, S Mohney and $T$ F Kelly, Fabncation of micromechancal devices from polysilicon films with smooth surfaces, Sensors and Actuators, 20 (1989) $117-122$

125 H Guckel, D K Showers, D W Burns, C K Nesler and C R Rutighiano, Deposition techniques and properties of strain compensated LPCVD silicon nitnde films, IEEE Solid-State Sensors Workshop, Hulton Head Island, SC, USA, June 6-9, 1986

126 S Sugyama, T Suzukı, K Kawahata, K Shımaoka, M Takıgawa and I Igarash1, Micro-diaphragm pressure sensor, Proc IEDM, Los Angeles, Caltfornia, USA, Dec 7-10, 1986, pp 184-187

127 O Tabata, K Shimaoka and S Sugiyama, In situ observation and analysis of wet etching process for micro electro mechanical systems, Proc IEEE Micro Electro Mechanical Systems, Nara, Japan, Jan 30-Feb 2, 1991, pp 99-102

128 M Parameswaran, H P Baltes, LJ Ristic, A C Dhaded and A $M$ Robinson, A new approach for the fabrication of micromechancal structures, Sensors and Actuators, 19 (1989) 298-307

$129 \mathrm{M}$ A Schmidt, R T Howe and S D Senturia, A micromachined floatıng-element shear sensor, Proc 4 th $\operatorname{lnt}$ Conf Soltd-State Sensors and Actuators (Transducers '87), Tokyo, Japan, June 2-5, 1987, pp 383-386

$130 \mathrm{~K}$ Ikeda, H Kuwayama, T Kobayashı, T Watanabe, T Nishıkawa, T Yoshida and $K$ Harada, Three-dimensional micromachınıng of silicon pressure sensor integrating resonant strain gauge on diaphragm, Sensors and Actuators, A21-A23 (1990) $1007-1010$

131 L Jastzebskı, J F Corboy, J T McGınn and R Pagliaro, Growth process of silicon over $\mathrm{S}_{1} \mathrm{O}_{2}$ by CVD epitaxial lateral overgrowth techniques, $J$ Electrochem Soc, 130 (1983) 1571 1580

132 H Guckel and D W Burns, Planar processed polysilicon sealed cavities for pressure transducer arrays, Proc IEEE Int Electron Devices Meet, San Francisco, CA, USA, Dec 9-12, 1984, pp 223-225

133 H Guckel, D W Burns, C C G Visser, H A C Tilmans and D W Deroo, Fine-grained polysilicon films with built-in tensile strain, IEEE Trans Electron Devices, ED-35(1988) 800801

134 H Guckel, D W Burns, H A C Tilmans, C C G Visser, D W DeRoo, T $\mathbf{R}$ Christenson, $P$ J Klomberg, J J Sniegowskı and D H Jones, Processing conditions for polysillcon films with tensile strain for large aspect ratio mucrostructures, IEEE Soldd-State Sensors Workshop, Hitton Head Island, SC, USA, June 6-9, 1988, pp 51-54

$135 \mathrm{~J}$ G E Gardenuers, MESA Research Institute, University of Twente, personal communication, May 1991

136 P Warth, Silicon fusion bonding for fabrication of sensors, Sensors and Actuators, A2I-A23 (1990) 919-926

137 H A C Tilmans, S Bouwstra, D J IJntema, M Elwenspoek and $C F$ Klein, A differential resonator design using a bossed structure for applications in mechanical sensors, Sensors and Actuators A, 25-27 (1991) 385-393

$138 \mathrm{H}$ L Offereins and $\mathrm{H}$ Sandmaier, Novel stress free assembly technique for micromechanical devices, Proc Micro System Technologies 90, Berlin, Germany, Sept 10-13, 1990, pp 515520

$139 \mathrm{~V}$ L Spiening, S Bouwstra, R M E J Spiering and $M$ Elwenspoek, On-chip decoupling zone for package-stress 
reduction, Proc 6th Int Conf Solld-State Sensors and Actuatars (Transducers '91), San Francisco, CA, USA, June 24-27, 1991, pp 982-985

$140 \mathrm{~F}$ Bordon1 and A D'Amico, Noise in sensors, Sensors and Actuators, A21-A23 (1990) 17-24
141 E Karrer and $\mathbf{R}$ Ward, A low-range quartz resonator pressure transducer, ISA Trans, 16 (1977) 90-98

142 M V Andres, K W H Foulds and M J Tudor, Sensitivity and mode spectrum of frequency-output silicon pressure sensor, Sensor and Actuators, 15 (1988) 417-426 